\title{
Efeito da transformação do ninho manual modelo holandês em mecânico na postura de ovos de cama em matrizes de frangos de corte
}

\author{
Fernando Pilotto ${ }^{1}$, Andréa Machado Leal Ribeiro², Alberto Cargnelutti Filho ${ }^{3}$, \\ Vilson Antonio Klein 4
}

\author{
${ }^{1}$ Departamento de Zootecnia, Programa de Pós-Graduação, Universidade Federal do Rio Grande do Sul (UFRGS), CEP: 91540-000, \\ Porto Alegre, RS, Brasil. \\ 2 Departamento de Pós Graduação em Zootecnia, UFRGS \\ ${ }^{3}$ Instituto de Matemática - Departamento de Estatística, UFRGS. \\ ${ }^{4}$ Faculdade de Agronomia e Medicina Veterinária (FAMV), Universidade de Passo Fundo (UPF).
}

RESUMO - Este trabalho visou adaptar o ninho manual modelo Holandês, cujo formato é bem aceito por matrizes de frangos de corte, a um modelo que permita fazer a coleta mecânica dos ovos. A adaptação consistiu em substituir a forração de maravalha por uma lâmina de madeira estofada e colocar uma correia de transporte para fazer o recolhimento dos ovos. Esta adaptação foi avaliada em dois experimentos no mesmo galpão, das 25 às 35 semanas de idade. Em ambos os experimentos, foram disponibilizados 69 módulos, cada um com 24 ninhos (ninho manual), para a coleta dos ovos de 7.690 galinhas e um módulo adaptado com 24 ninhos (ninho mecânico) para a coleta mecânica dos ovos de 110 galinhas. No primeiro experimento, foram comparadas as porcentagens semanais de ovos produzidos e de ovos de cama e, no segundo experimento, além dessas variáveis, foram observadas as porcentagens de ovos trincados e de ovos sujos de ninho. Também no experimento 2, visando reduzir os ovos postos na cama observados no experimento 1, foi colocada maravalha sobre a forração desenvolvida, do alojamento até 26 $6^{\text {a }}$ semana. Utilizou-se um esquema fatorial $2 \times 11$, no qual a parcela principal foi constituída pelos ninhos mecânico e manual e as subparcelas pelas 11 semanas de avaliação. A porcentagem semanal de ovos produzidos foi semelhante entre os dois tipos de ninho, tanto no experimento 1 como no experimento 2. As porcentagens de ovos cama (experimentos 1 e 2), ovos sujos e ovos trincados (experimento 2) obtidas com o ninho mecânico foram maiores que com o ninho manual. No experimento 2, a colocação de maravalha no ninho mecânico não contribuiu para a redução da porcentagem de ovos de cama. A transformação do ninho manual em mecânico aumentou o número de ovos postos na cama, de ovos trincados e de ovos sujos, comprovando pior aceitação desse tipo de ninho pelas galinhas.

Palavras-chave: matrizes de frangos de corte, ninhos, ovos de cama

\section{Effect of the transformation of a hand-operated Dutch nest into a mechanical nest on the laying of floor eggs in broiler breeders}

\begin{abstract}
This experiment aimed at adapting the Dutch manual nest model, whose format is well accepted by the parental broiler lines, to a new model aiming the mechanical egg collection. Adaptation consisted on replacing wood shaving by stuffed wood sheet and the placement of a conveyor belt for egg collection. This adaptation was evaluated in two experiments in the same shed with breeders from 25 to 35 weeks of age. In both experiments, there were 69 available modules, each one with 24 nests (manual nest) for collection of eggs from 7,690 hens and one adapted module with 24 nests (mechanical nest) for mechanical collection of eggs from 110 hens. In experiment 1, weekly percentages of produced eggs and floor eggs were compared and in experiment 2, besides those variables, percentages of cracked eggs and dirty eggs in the nest were observed. Also in experiment 2, aiming to reduce floor eggs observed in experiment 1, wood shavings were added on the stuffed wood sheet, from lodging to the $26^{\text {th }}$ week. It was used a $2 \times 11$ factorial design, in which the main plot was constituted by the mechanical and manual nests and the sub-plots were composed of the eleven weeks of evaluation. The weekly percentage of produced weeks was similar for the two nest types, in both 1 and 2 experiments. Percentage of floor eggs (experiments 1 and 2), dirty eggs and cracked eggs (experiment 2) obtained with mechanical nest were worse than with manual nest. In experiment 2, placement of wood shavings in the mechanical nest did not contribute for reduction on floor egg percentage. Transformation of manual nest to mechanical nests increased the number of floor, dirty and cracked eggs, showing a worse acceptance of this type of nest by the hens.
\end{abstract}

Key Words: floor egg, nests, parental broiler lines 


\section{Introdução}

No Brasil, a coleta dos ovos na maioria das granjas de matrizes de corte é feita em ninhos manuais, principalmente em razão do elevado custo dos ninhos mecânicos disponíveis no mercado e de sua menor aceitação pelas aves, elevando o número de ovos postos na cama (Appleby, 1984). Entretanto, os ninhos manuais requerem mais mão-de-obra para seu manuseio que os ninhos mecânicos. A coleta mecânica dos ovos reduz em aproximadamente 60 a 70\% o tempo de coleta em relação ao ninho manual, permitindo que o funcionário dedique mais tempo ao manejo com as aves (Wilson, 1996).

Holcman et al. (2007), observaram que galinhas preferem ninhos forrados com maravalha a ninhos forrados com tapetes de plástico. O ninho forrado com maravalha, além de dar mais conforto à ave, permite que a galinha faça facilmente sua concavidade através de movimentos em círculos antes da postura (Wood-Gush, 1954). Por outro lado, Brake (1985) não observou diferença na postura de ovos de cama quando disponibilizaram para as aves ninhos mecânicos revestidos com tapete ou com maravalha.

Duncan \& Kite (1989) verificaram que as galinhas preferem fazer a postura em ninhos com fundo côncavo em comparação a ninhos com fundo plano. Na natureza, as aves fazem o ninho côncavo para que os ovos fiquem agrupados, facilitando o aquecimento durante o choco e evitando que rolem para fora do ninho (Caranza, 2000), uma preferência também das matrizes criadas em galpões (Kite et al., 1980). Contrariamente, nos ninhos mecânicos utiliza-se forração com materiais como tapetes de plástico, que fazem os ovos rolarem para fora do ninho.

Com o objetivo de atrair as galinhas ao ninho, práticas de manejos são realizadas no período inicial de postura, como a colocação de maravalha sobre a forração do ninho mecânico (Pitt, 1983). Segundo Wilson (1996), esse manejo inicial é de extrema importância, visto que a maioria das galinhas define o local de postura nas primeiras cinco semanas de produção.

O desenvolvimento de novos materiais higiênicos para forração dos ninhos, que tenham boa aceitação pelas galinhas, e que possibilitem a coleta mecânica dos ovos tem sido o grande desafio na mecanização da coleta dos ovos em granjas de matrizes de frangos de corte. Este trabalho foi realizado com o objetivo de avaliar uma nova forração, visando adaptar o ninho manual modelo holandês a um sistema mecânico para coleta dos ovos.

\section{Material e Métodos}

O ninho modelo holandês (manual) apresenta em cada módulo 12 ninhos na parte superior e 12 na parte inferior, sendo 6 em cada lado do equipamento, em ambas as alturas, e forrado com maravalha (Figura 1).

A mudança realizada neste equipamento com o intuito de transformá-lo num sistema mecânico de coleta (ninho mecânico) foi a utilização de uma forração que permitisse que os ovos, após a postura, rolassem para fora do ninho. A forração desenvolvida foi composta de uma lâmina de madeira envolvida por uma camada de espuma e revestida por uma lona de algodão encerada. A camada de espuma (densidade nominal de $33 \mathrm{~kg} / \mathrm{m}^{3}$ ) apresentava $5 \mathrm{~cm}$ de espessura e foi colocada com o objetivo de oferecer uma superfície mais confortável para as aves fazerem a postura. A lâmina estofada foi encaixada no fundo dos ninhos e disposta num ângulo de 15 graus de inclinação para o centro do módulo, de modo que os ovos rolassem para fora dos ninhos. Na linha central dos ninhos, tanto na parte inferior quanto superior do módulo, foi colocada uma correia com $15 \mathrm{~cm}$ de largura para armazenar os ovos que rolavam para fora dos ninhos. Essa correia, quando tracionada manualmente com auxílio de uma catraca, transportava os ovos para um único ponto, onde era feita a coleta. O transporte dos ovos até a mesa de coleta, tanto da parte inferior quanto superior do módulo mecânico, foi realizado pela mesma correia. Para isso ser possível, os ovos provenientes da parte inferior foram transportados até o final do módulo (sentido oposto à mesa de coleta), onde por outra correia paralela, foram conduzidos para a parte superior e assim transportados, juntamente como os ovos provenientes dos ninhos situados na parte superior do módulo, até a mesa de coleta (Figura 2).

A avaliação do desempenho do ninho mecânico em relação ao ninho manual foi realizada em dois experimentos

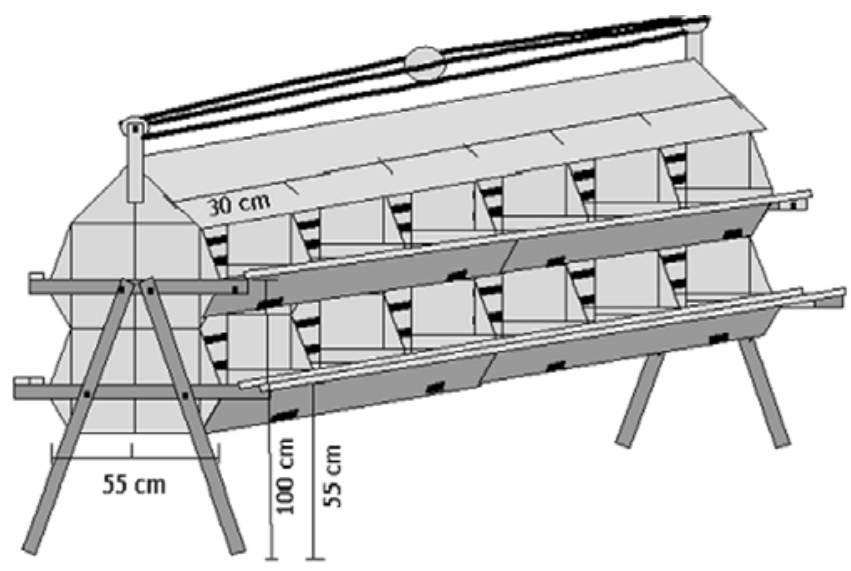

Figura 1 - Ninho manual modelo Holandês. 
consecutivos no mesmo galpão de matrizes de corte. Em cada experimento foram alojadas 7.800 galinhas e 800 machos da linhagem Cobb 500 com 22 semanas de idade. Desse total, no alojamento 110 fêmeas e 11 machos foram separados com uma tela do restante do lote e a eles foi disponibilizado o ninho mecânico. No experimento 1, foi disponibilizado o ninho mecânico do alojamento até as 35 semanas de idade, para comparação ao modelo manual. No segundo experimento, foi colocada uma camada de maravalha de aproximadamente $10 \mathrm{~cm}$ de altura sobre a forração estofada do alojamento até as 26 semanas com o objetivo de tornar o ninho mecânico mais atrativo para as galinhas fazerem a postura. A partir das 26 semanas, a maravalha começou a ser retirada gradualmente e foi totalmente removida no início das 27 semanas. Nos dois experimentos as condições de alojamento inicial (4,5 galinhas/ninho, 6,0 aves $/ \mathrm{m}^{2}$, 100 aves/bebedouro tipo pendular, $13,5 \mathrm{~cm}$ de comedouro/ fêmea) e de manejo (17 horas de luz/dia, manejo de cortina, quantidade de ração fornecido por ave/dia, 5 coletas de ovos/dia) foram as mesmas nos dois grupos. No ninho manual foram coletados ao longo das 11 semanas de avaliação no primeiro e no segundo experimento 388.976 e 395.978 ovos e no ninho mecânico 5.455 e 5.627 ovos, respectivamente.

A avaliação dos experimentos foi realizada das 25 às 35 semanas de idade. No experimento 1 , foram comparadas a produção diária de ovos e a porcentagem de ovos de cama e, no experimento 2 , além dessas variáveis, também foram avaliados o número de ovos trincados e de ovos sujos de ninho. No ninho mecânico, diariamente no final da tarde, o fundo era removido e a face disposta para as aves fazerem a postura foi escovada e recolocada novamente. Esse procedimento foi realizado no experimento 1 desde o alojamento e, no experimento 2, a partir das 27 semanas, quando foi removida toda a maravalha dos ninhos. Nos ninhos manuais e no experimento 2 no ninho

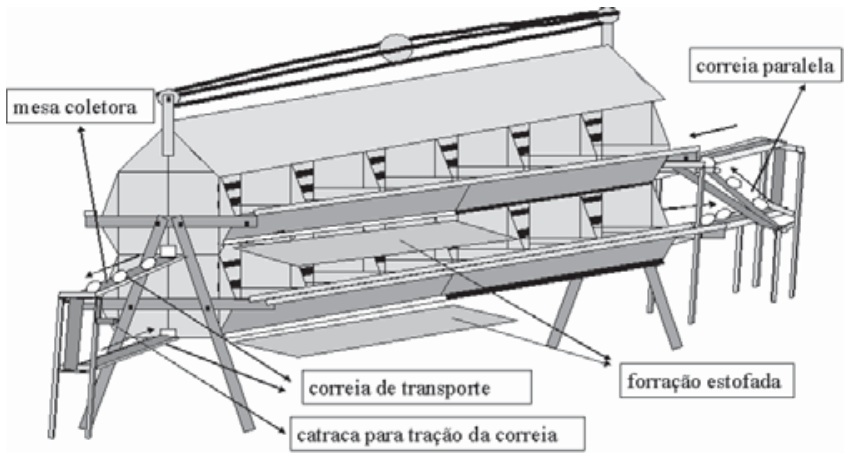

Figura 2 - Ninho modelo Holandês adaptado para fazer a colheita mecânica dos ovos. mecânico até as 26 semanas, a maravalha foi reposta a cada 15 dias.

Os dados dos experimentos 1 e 2 foram submetidos à análise de variância, em um delineamento inteiramente casualizado, com 7 repetições, em esquema fatorial $2 \times 11$ com parcela subdividida no tempo. A parcela principal foi constituída pelos dois sistemas de coleta (ninho manual e mecânico) e a subparcela pelas 11 semanas de avaliação. Cada dia da semana foi considerado uma repetição.

\section{Resultados e Discussão}

A porcentagem total de ovos produzidos das 25 às 35 semanas foi semelhante $(\mathrm{P}>0,05)$ entre os dois tipos de ninho e entre os dois experimentos. Na $25^{\underline{a}}$ semana, as aves de ambos os tipos de ninho estavam colocando em média $12 \%$ de ovos (experimento 1) e $20 \%$ (experimento 2), alcançando o pico de $84 \%$ na 30 a semana, mantendo-se, até a 35 a semana, em torno de $80 \%$ de produção. As modificações feitas no ninho manual com o objetivo de fazer a coleta mecânica dos ovos não influenciaram a porcentagem de ovos produzidos por galinha.

Para a porcentagem de ovos postos na cama, foi observada interação ninho $\times$ semana de avaliação $(P<0,05)$, evidenciando que essa variável é influenciada pelo tipo de ninho ao longo do período de avaliação (Tabelas 1 e 2). A interação foi observada em ambos os experimentos. As galinhas tenderam a rejeição do ninho mecânico em ambos os experimentos, colocando em torno de $67 \%$ dos ovos na cama na 27ㅁa e 28ㅁa semanas de idade e depois estabilizando a partir da semana 31 em 35\%, enquanto no ninho manual houve um pico de 9\% na postura de ovos de cama nas 26 semanas e estabilizando-se em $3 \%$ a partir das 30 semanas.

As alterações no ninho manual não tiveram boa aceitação pelas aves e refletiram em maior porcentagem de ovos postos na cama em ambos os experimentos. No experimento 2, a adição de maravalha sobre a lâmina estofada das 22 às 26 semanas de idade, no início da produção de ovos, fez com que na 25 a semana não tenha sido verificada diferença na postura de ovos de cama entre os dois tipos de ninho $(\mathrm{P}>0,05)$. Entretanto, a partir das 26 semanas, quando foi iniciada a retirada gradual de maravalha, a porcentagem de ovos de cama no ninho mecânico aumentou. Das 27 às 35 semanas esta porcentagem atingiu índices semelhantes ao do primeiro experimento. Isto mostra que o período de treinamento inicial não contribuiu na redução da postura de ovos de cama, como era esperado. Appleby \& Smith (1991), testando diferentes modelos de ninhos em poedeiras comerciais observaram aumento de $40 \%$ na postura de ovos no ninho 
quando foi colocada maravalha, e redução de $60 \%$ quando a mesma foi retirada. Isto também aconteceu no experimento 2, quando houve um rápido aumento na postura de ovos de cama com a retirada parcial da maravalha nos ninhos na 26ㅁa semana, e total a partir da 27모 semana. Petherick et al. (1993), estudando diferentes níveis de maravalha nos ninhos, observaram que as galinhas preferem os ninhos com maior quantidade de forração a ninhos com pouca ou nenhuma maravalha.

Nos dois experimentos foi observado que nas $27^{\mathrm{a}}$ e $28^{\mathrm{a}}$ semanas, houve um pico de postura de ovos de cama, seguido de uma redução nas semanas 29,30 e 31 e estabilizando-se nas semanas seguintes. Nos ninhos manuais a maior postura de ovos de cama foi observada entre a $25^{\mathrm{a}}$ e $27^{\mathrm{a}}$ semanas, reduzindo nas $28^{\mathrm{a}}$ e $29^{\mathrm{a}}$ semanas, e estabilizando-se a partir das 30 semanas. No ninho mecânico, houve maior rejeição no início do período de produção, comparados aos ninhos manuais. Observa-se também, em função dessa maior rejeição, que a redução na produção de ovos de cama até estabilizar-se foi mais lenta no ninho mecânico. $\mathrm{O}$ fato de ocorrer uma maior porcentagem de ovos de cama no início da produção, em ambos os tipos de ninho, se deve ao fato das aves estarem pondo os primeiros ovos e ainda estarem num período de aprendizado quanto ao local onde irão fazer a postura.

Na natureza, as galinhas constroem seu ninho com o objetivo de fazer a postura dos ovos e posteriormente chocá-los para assim perpetuar sua espécie. O ninho manual, diferentemente do mecânico, além de dar mais conforto ao animal, permite que a galinha faça concavidade por meio movimentos rotativos em círculos antes da postura (Wood-Gush, 1954). Nas granjas de matrizes de corte, mesmo que os ovos sejam coletados várias vezes ao dia, as aves não desenvolvem o comportamento de choco e, antes de fazerem a postura dos ovos, recolhem com o bico para baixo de si todos os ovos que já estão no ninho, demonstrando claramente a intenção de chocá-los. Desta forma, a menor aceitação dos ninhos mecânicos também pode estar associada à rolagem dos ovos para cima da correia de transporte após a postura, não permitindo a presença de ovos no ninho, como ocorre com os ninhos manuais. Kite et al. (1980) demonstraram que as aves preferem ninhos nos quais os ovos fiquem depositados após a postura. De forma que, deixar ovos nos ninhos, no início do período de produção, pode ser uma maneira de torná-los mais atrativos.

No experimento 2, também foi avaliada a higiene do ninho, pela porcentagem de ovos sujos de ninho, e a porcentagem de ovos trincados. Não houve diferença na porcentagem de ovos sujos de ninho na 25a e $26^{\underline{a}}$ semanas $(\mathrm{P}>0,05)$, uma vez que foi utilizada maravalha sobre o fundo estofado (Tabela 2). A partir da $27^{\mathrm{a}}$ semana, a porcentagem de ovos sujos de ninho foi aumentando de acordo com o aumento da idade das galinhas, somente no ninho mecânico. A forração estofada, mesmo sendo escovada no final do dia e permitindo que os ovos rolassem para fora no ninho, não conseguiu absorver a sujidade levada pelos pés das galinhas, aumentando a porcentagem de ovos sujos, na medida em que a qualidade da cama piorava com o envelhecimento do lote. O ninho manual apresentou menor porcentagem de ovos sujos, uma vez que a maravalha absorve a sujeira que é levada para dentro dos ninhos pelas galinhas. Brake (1985), utilizando tapetes de plástico com cerdas longas na forração dos ninhos, observou menor contaminação dos ovos em relação ao uso de maravalha. Nesta situação, os tapetes utilizados permitiram que a sujeira ficasse acumulada entre as cerdas, impedindo a sujidade dos ovos, condição esta não oferecida pela forração estofada desenvolvida, pois apresentava superfície lisa.

A porcentagem de ovos trincados também foi maior nos ninhos mecânicos que nos ninhos manuais, a partir da

Tabela 1 - Porcentagem semanal de ovos produzidos e de ovos de cama nos ninhos com coleta mecânica e manual (experimento 1)

\begin{tabular}{|c|c|c|c|c|}
\hline \multirow[t]{2}{*}{ Semana } & \multicolumn{2}{|c|}{$\%$ semanal de ovos produzidos } & \multicolumn{2}{|c|}{ \% ovos de cama } \\
\hline & Ninho mecânico & Ninho manual & Ninho mecânico & Ninho manual \\
\hline 25 & $12,50 \mathrm{a}$ & $15,30 \mathrm{a}$ & $54,70 a$ & $5,18 b$ \\
\hline 26 & $24,80 \mathrm{a}$ & $26,40 a$ & $65,24 a$ & $8,02 b$ \\
\hline 27 & $45,90 a$ & $45,30 a$ & $66,87 a$ & $7,87 b$ \\
\hline 28 & $65,70 a$ & $62,10 \mathrm{a}$ & $66,31 \mathrm{a}$ & $6,03 b$ \\
\hline 29 & $80,30 a$ & $78,40 a$ & $58,76 a$ & $4,66 \mathrm{~b}$ \\
\hline 30 & $83,90 a$ & $84,20 a$ & $46,48 a$ & $3,13 b$ \\
\hline 31 & $83,20 a$ & $83,80 a$ & $35,23 a$ & $2,75 b$ \\
\hline 32 & $83,60 a$ & $83,50 a$ & $33,15 a$ & $2,65 b$ \\
\hline 33 & $82,78 a$ & $82,60 a$ & $34,80 a$ & $2,80 b$ \\
\hline 34 & $81,90 a$ & $81,50 a$ & $32,92 \mathrm{a}$ & $2,71 b$ \\
\hline 35 & $80,85 a$ & $80,80 \mathrm{a}$ & $34,04 \mathrm{a}$ & $2,78 b$ \\
\hline Média & $65,94 a$ & $65,80 \mathrm{a}$ & $48,00 \mathrm{a}$ & $4,4 \mathrm{~b}$ \\
\hline
\end{tabular}

Médias com letras diferentes na mesma linha para o mesmo parâmetro avaliado indicam diferença $(\mathrm{P}<0,05)$ pelo teste Tukey. 
Tabela 2 - Porcentagem semanal de ovos produzidos, ovos de cama, ovos sujos de ninho e ovos trincados nos ninhos com coleta mecânica e manual (experimento 2)

\begin{tabular}{|c|c|c|c|c|c|c|c|c|}
\hline \multirow[b]{2}{*}{ Semana } & \multicolumn{2}{|c|}{$\%$ semanal de ovos produzidos } & \multicolumn{2}{|c|}{$\%$ ovos de cama } & \multicolumn{2}{|c|}{ \% ovos sujos de ninho } & \multicolumn{2}{|c|}{$\%$ ovos trincados } \\
\hline & $\begin{array}{c}\text { Ninho } \\
\text { mecânico }\end{array}$ & $\begin{array}{l}\text { Ninho } \\
\text { manual }\end{array}$ & $\begin{array}{c}\text { Ninho } \\
\text { mecânico }\end{array}$ & $\begin{array}{l}\text { Ninho } \\
\text { manual }\end{array}$ & $\begin{array}{c}\text { Ninho } \\
\text { mecânico }\end{array}$ & $\begin{array}{l}\text { Ninho } \\
\text { manual }\end{array}$ & $\begin{array}{c}\text { Ninho } \\
\text { mecânico }\end{array}$ & $\begin{array}{l}\text { Ninho } \\
\text { manual }\end{array}$ \\
\hline 25 & $22,47 a$ & $24,36 a$ & $7,28 a$ & $8,53 a$ & $2,71 \mathrm{a}$ & $3,26 \mathrm{a}$ & $0,60 \mathrm{a}$ & $0,75 a$ \\
\hline 26 & $34,48 a$ & $36,82 \mathrm{a}$ & $28,87 \mathrm{a}$ & $9,22 b$ & $5,52 \mathrm{a}$ & $4,84 \mathrm{a}$ & $0,79 a$ & $0,63 a$ \\
\hline 27 & $47,78 a$ & $47,09 a$ & $65,72 \mathrm{a}$ & $7,66 \mathrm{~b}$ & $7,32 \mathrm{a}$ & $4,30 \mathrm{~b}$ & $1,13 \mathrm{a}$ & $0,78 a$ \\
\hline 28 & $65,87 a$ & $64,81 \mathrm{a}$ & $67,30 a$ & $5,81 b$ & $10,75 a$ & $3,12 b$ & $1,17 \mathrm{a}$ & $0,57 \mathrm{a}$ \\
\hline 29 & $80,23 a$ & $79,79 a$ & $53,15 a$ & $4,24 b$ & $13,73 a$ & $3,04 b$ & $1,32 \mathrm{a}$ & $0,37 b$ \\
\hline 30 & $85,85 a$ & $84,97 a$ & $38,02 \mathrm{a}$ & $3,64 b$ & $16,65 a$ & $3,20 b$ & $1,09 \mathrm{a}$ & $0,47 \mathrm{~b}$ \\
\hline 31 & $83,71 \mathrm{a}$ & $83,18 a$ & $36,52 \mathrm{a}$ & $2,79 b$ & $21,55 a$ & $3,89 b$ & $1,29 a$ & $0,54 b$ \\
\hline 32 & $83,04 a$ & $82,58 a$ & $33,59 a$ & $2,66 b$ & $24,44 a$ & 3,92b & $1,30 \mathrm{a}$ & $0,56 b$ \\
\hline 33 & $82,51 \mathrm{a}$ & $81,98 a$ & $34,34 a$ & $2,69 b$ & $26,40 a$ & $3,87 b$ & $1,32 \mathrm{a}$ & $0,58 b$ \\
\hline 34 & $81,84 a$ & $81,61 \mathrm{a}$ & $33,15 a$ & $2,83 b$ & $27,42 \mathrm{a}$ & 3,97b & $1,49 \mathrm{a}$ & $0,51 b$ \\
\hline 35 & $80,37 a$ & $80,56 a$ & $34,00 a$ & $2,82 b$ & $28,00 \mathrm{a}$ & $4,24 b$ & $1,50 \mathrm{a}$ & $0,50 b$ \\
\hline Média & $68,01 \mathrm{a}$ & $67,97 a$ & $39,27 a$ & $4,81 b$ & $17,04 \mathrm{a}$ & $3,79 b$ & $1,20 \mathrm{a}$ & $0,57 b$ \\
\hline
\end{tabular}

Médias com letras diferentes na mesma linha para o mesmo parâmetro avaliado indicam diferença $(\mathrm{P}<0,05)$ pelo teste Tukey.

27ạ semana (Tabela 2). Esse aumento pode estar associado a problemas de estrutura do ninho, como forração muito inclinada e correia transportadora estreita, fazendo com que os ovos rolassem rapidamente para fora do ninho atritando-se com os ovos que já estavam sobre a correia ou na borda da calha que sustentava a correia de transporte.

As adaptações realizadas no ninho manual modelo Holandês, com o objetivo de realizar a coleta mecânica dos ovos, embora tenham facilitado a coleta dos ovos postos no ninho, não reduziu a mão de obra, pelo contrário, gerou mais trabalho para coletar e limpar a elevada porcentagem de ovos postos na cama e para limpar os ovos sujos de ninho. Os resultados deste trabalho demonstram que a forração utilizada nos ninhos exerce forte influência na sua aceitação pelas galinhas. Desta forma, o desenvolvimento de ninhos mecânicos que possibilitem a presença dos ovos no ninho após sua postura e utilização de materiais como a maravalha na sua forração, talvez sejam a solução para manter os resultados zootécnicos alcançados com os ninhos manuais.

\section{Conclusões}

As adaptações realizadas no ninho manual com objetivo de transformá-lo em mecânico provocam aumento no número de ovos de cama, ovos trincados e ovos sujos de ninho em relação ao ninho manual forrado com maravalha. A utilização de maravalha sobre a lâmina estofada nas primeiras semanas não reduz a postura de ovos de cama nas semanas posteriores.

\section{Agradecimentos}

À Doux Frangosul S.A. Agro Avícola Industrial.

À bolsa de produtividade em Pesquisa do CNPq de Alberto Cargnelutti Filho.

\section{Referências}

APPLEBY, M.C.; SMITH, S.F. Design of nest boxes for laying cages. Britsh Poultry Science, v.32, p.667-678, 1991.

APPLEBY, M.C. Factors affecting floor laying by domestic hens: A review. World's Poultry Science Journal, v.40, p.241-249, 1984.

BRAKE, J. Comparison of two nesting materials for broiler breeders. Poultry Science, v.64, p.22263-2266, 1985.

CARANZA, J. Introducción a la ciencia del comportamiento. Madrid: Universidad de Extremadura, 2000. 590p.

DUNCAN, I.J.H.; KITE, V.G. Nest site selection and nest-building behaviour in domestic fowl. Animal Behaviour, v.37, p.215-231, 1989.

HOLCMAN, A.; MALOVRH, S.; STUHEC. I. Choice of nest by hens of three lines of broiler breeders. British Poultry Science, v.48, p.284-290, 2007.

KITE, V.C.; WOODS, R.E.; LAURENT, C.K. et al. Nesting behaviour of hens in relation to the problem of floor eggs. Reviews in Rural Science IV, v.3, p.93, 1980.

PETHERICK, J.C.; SEAWRIGHT, E.; WADDINGTON, D. et al. Influence of quantity of litter on next box selection and nesting behaviour of domestic hens. British Poultry Science, v.34, p.857-872, 1993.

PITT, M. The production of non-cage eggs in seven North European Countries. World's Poultry Science Journal, v.40, p.241-249, 1983.

WILSON, J. Mechanical egg collection in broiler breeder houses. Poultry-Misset International, v.12, p.41-45, 1996

WOOD-GUSH, D.G.M. Observations on the nesting habits of Brown Leghorn hens. Poultry Research Centre, v.10, p.187-192, 1954. 